\title{
Perioperative management of the new oral anticoagulants: are Portuguese General Practiotioners aware of the Portuguese Society of Anesthesiology Consensus?
}

\author{
António Cruz-Ferreira ${ }^{1,2}$, Teresa Lugarinho-Monteiro ${ }^{3}$ \\ 1- General Practitioner at Mealhada Primary Healthcare Unit, Mealhada (Portugal); 2- PhD Candidate at Faculty of Health Sciencies of University of Beira \\ Interior, Covilha (Portugal); 3- Anesthesiology trainee at Coimbra University and Hospital Center, Coimbra (Portugal)
}

\section{Background and Goal of Study:}

In Portugal, it's usual for patients to approach GPs with questions regarding the perioperative management of the new oral anticoagulants(NOA) prior undergo endoscopic procedures or minor surgeries.

Regarding the best practices and patients welfare, the Portuguese Society of Anesthesiology (PSA) released the 2014 Consensus on perioperative management of anticoagulants/ antiaggregants.

We aimed to assess the knowledge of a group of Portuguese GPs and trainees regarding this important field of their practice.

\section{Materials and Methods:}

In a GPs meeting, we requested volunteers to fulfill a questionnaire comprising 2 groups of questions (figure 1 ):

Firstly, we asked to identify the risk of bleeding of 10 different surgeries.

Secondly, we asked to answer true or false to 8 pharmacology related questions regarding the perioperative management of NOA.

Data related to the level of training and the previous knowledge of the Consensus were collected.

Participants were divided in three groups:

- General Practitioners (GP),

- Trainee within their first 2 years of training (Trainee FY)

- GP Trainees

Descriptive and inferential statistics were performed using SPSS v.20.0.

Results and Discussion:

A total of 30 GPs and trainees answered our questionnaire (11 GPs, 5 trainees within first 2 years, and 14 senior trainees).

Only $3(10 \%)$ had read the PSA Consensus.

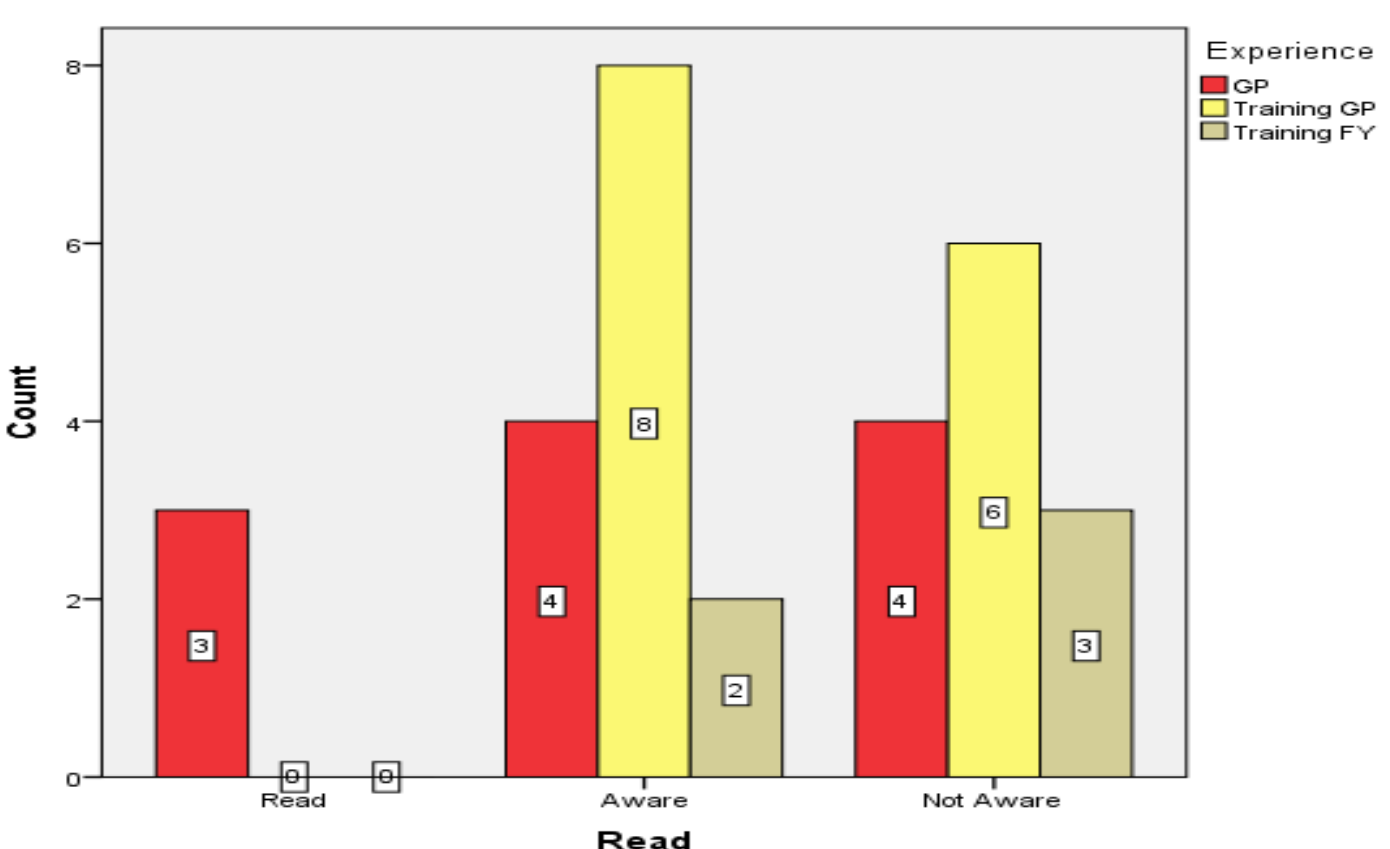

Regarding the risk stratification surgeries: $40 \%$ only identified correctly $\leq 4$ surgeries and $70 \%$ to $\leq 6$.

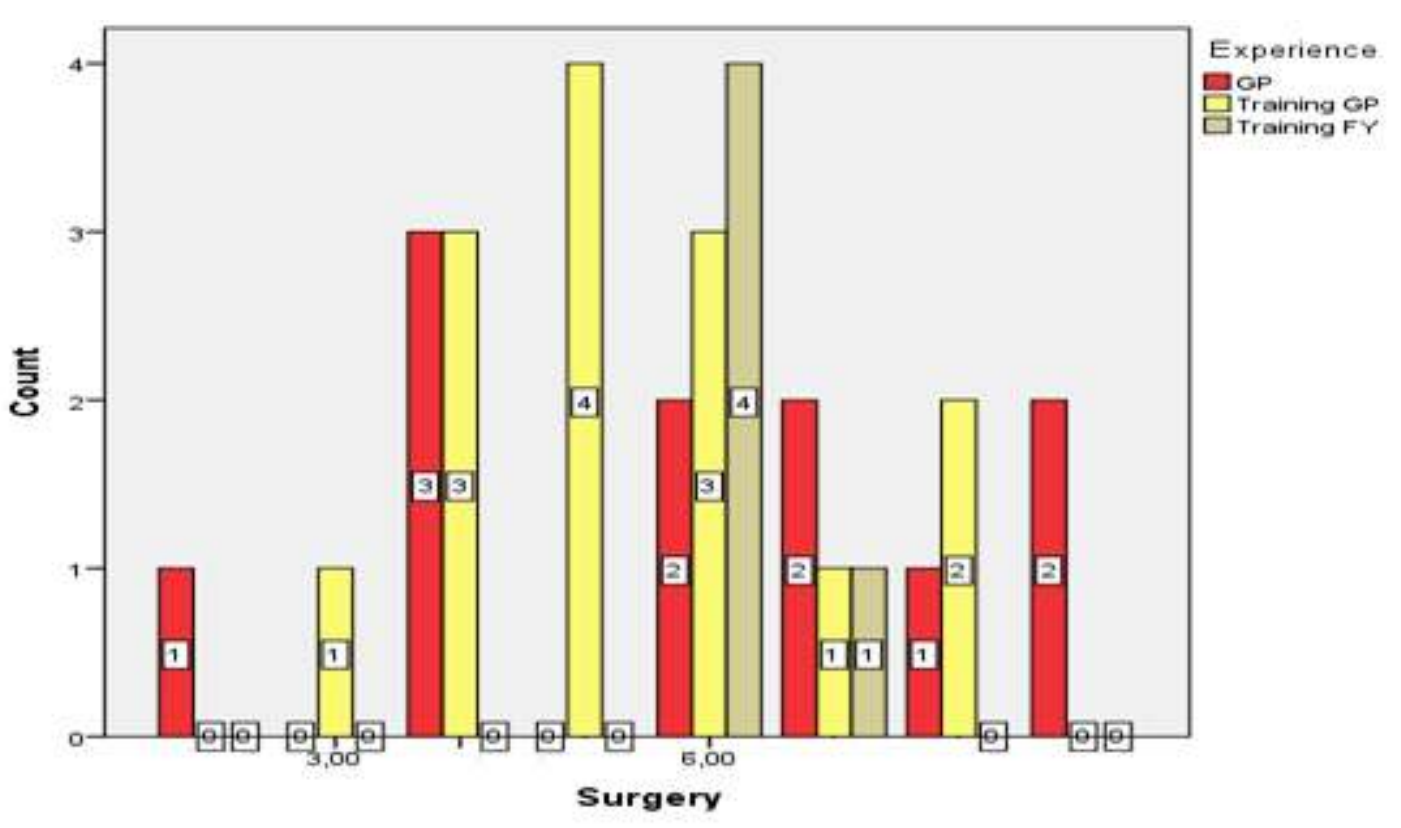

Similar scores were recorded for the pharmacological aspects of the NOA, with $43 \%$ answering correctly to $\leq 4$ questions and $90 \%$ to $\leq 6$.

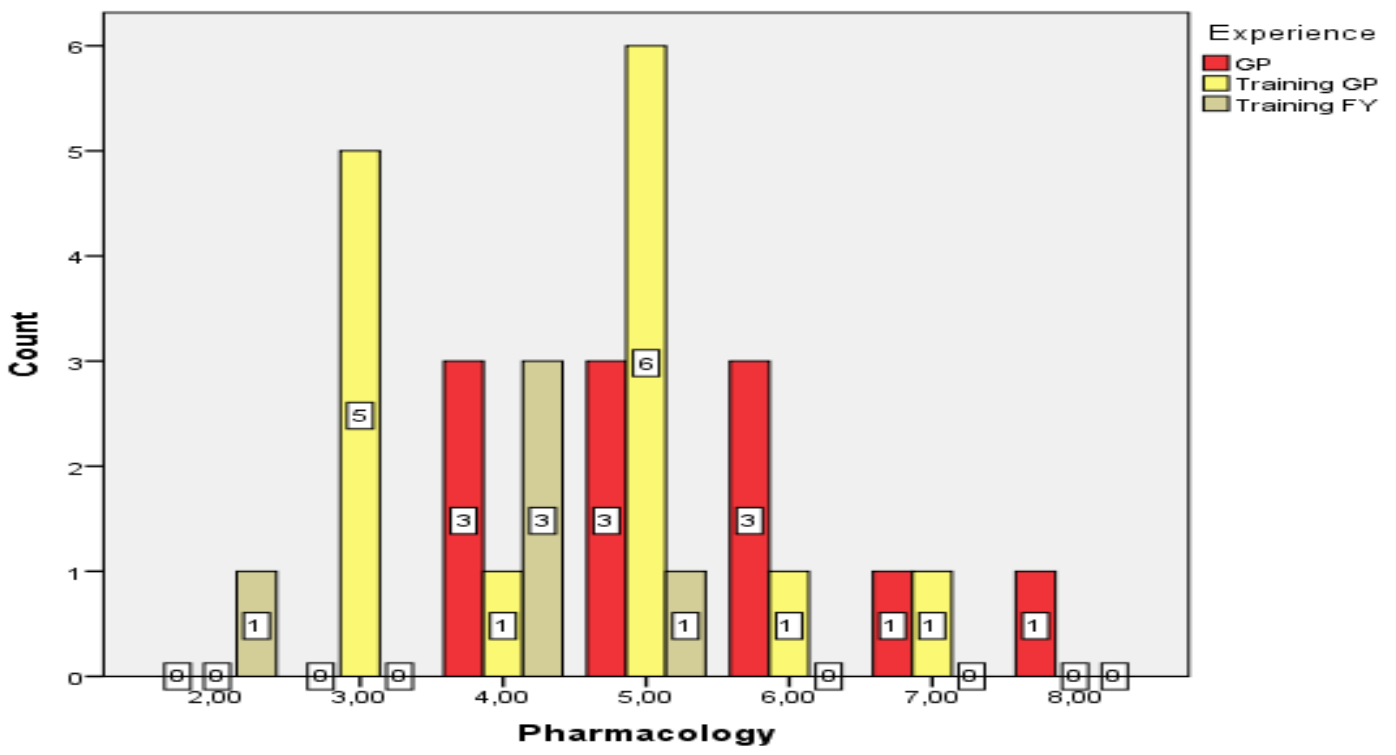

No significant differences were found between the different groups ( $p=.057$ for pharmacology; $p=.468$ for surgeries: using Kruskal Walis test).

These results reflect the lack of awareness of GPs regarding the relevant document issued by the PSA, with a minority of the participants answering correctly to at least half of the questions.

\section{Conclusion:}

1. Safety and welfare of patients using NOA is a major concern and valid instruments as the PSA Consensus statement can help to standardize procedures among health professionals, and raise the quality of their practice.

2. Both GPs and Anesthesiologists should actively cooperate in order to spread the awareness among clinicians usually engaged in the perioperative management of NOA. 